\title{
latrogenic biloma: a rare and delayed complication of a life-saving transarterial hepatic embolisation
}

\author{
Amit R Hudgi (1) , ${ }^{1}$ Haoran Peng, ${ }^{2}$ Subbaramia Sridhar, ${ }^{2}$ John Erikson Yap (i) ${ }^{2}$
}

${ }^{1}$ Internal Medicine, Augusta University Medical College of Georgia, Augusta, Georgia, USA ${ }^{2}$ Division of Gastroenterology and Hepatology, Augusta University Medical College of Georgia, Augusta, Georgia, USA

\section{Correspondence to} Dr Amit R Hudgi; amithudgi@gmail.com

Accepted 6 August 2021

\section{DESCRIPTION}

A 29-year-old African-American man was admitted after a motor vehicle accident (MVA). He was an unrestrained driver, ejected from the vehicle which struck a stationary pole. He had significant blunt trauma to face, chest, abdomen and left lower extremity. CT angiography (CTA) of the abdomen showed a grade-4 liver injury with complex stellate laceration disrupting segments $4 \mathrm{~A}, 4 \mathrm{~B}, 5,8$ and the caudate lobe. There were a few foci of possible venous bleed but no obvious active arterial bleeding was noted. The patient underwent hepatic angiogram, which showed a large laceration in the segment 8 . A $0.4 \mathrm{~cm}$ segment 4 pseudoaneurysm and a $0.6 \mathrm{~cm}$ segment 8 pseudoaneurysm were noted during the procedure with possible developing tract connection between the two segments. Selective gel foam embolisation of segment 8 hepatic arterial branch was performed successfully. A repeat CTA performed 1-day post-transarterial hepatic artery embolisation confirmed no active bleeding. On postoperative day 9, the patient developed persistent low-grade fever of $37.8^{\circ} \mathrm{C}$. The laboratory values were significant for elevated white cell count of $14 \times 10^{9} / \mathrm{L}$, total bilirubin of $1.6 \mathrm{mg} / \mathrm{dL}$, aspartate transaminase of $126 \mathrm{U} / \mathrm{L}$, alanine transaminase of $126 \mathrm{U} / \mathrm{L}$ and alkaline phosphatase of $164 \mathrm{U} / \mathrm{L}$. A repeat CT scan of the abdomen was performed which revealed a new $3.1 \times 2 \mathrm{~cm}$ cystic region of fluid density identified between segments 2 and 4 (figure 1).

This localised collection was identified as a biloma which is a rare complication after transarterial embolisation. He was placed on empiric antibiotics of ceftriaxone and metronidazole, later underwent endoscopic ultrasound-guided drainage as well as endoscopic retrograde cholangiopancreatography (ERCP) with sphincterotomy and temporary plastic bile duct stent placement. A total of $5 \mathrm{~mL}$ bilious fluid from the anechoic rounded area

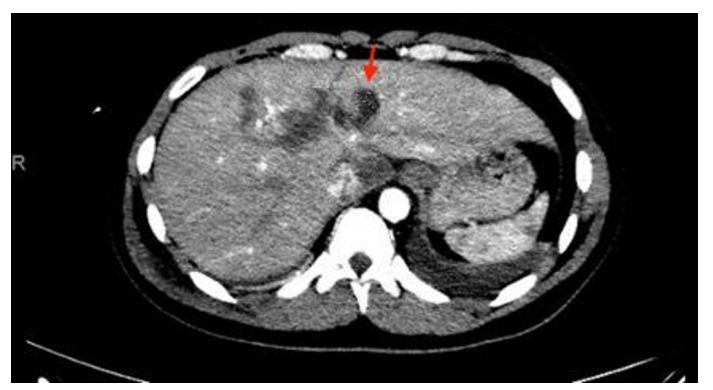

Figure 1 CT scan of the abdomen showing a $20.5 \times 31.3 \mathrm{~mm}$ size biloma identified as a complication of the transarterial embolisation procedure.

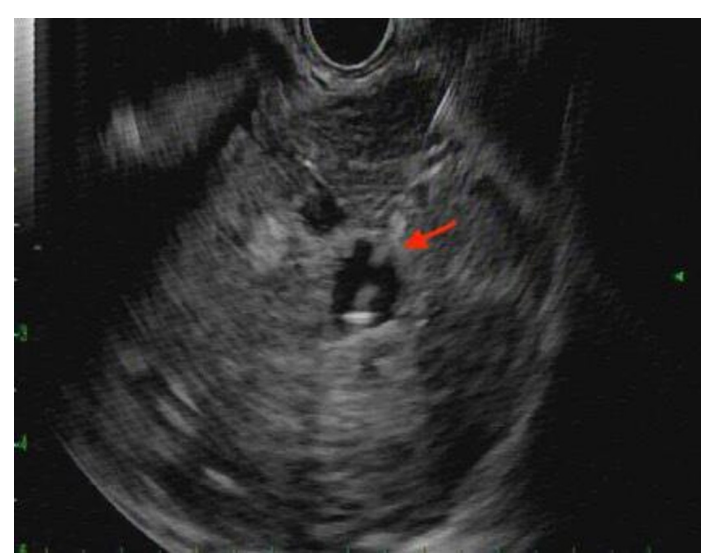

Figure 2 Fine-needle aspiration of the biloma $(3.1 \times 2$ $\mathrm{cm}$, annotated above) under the guidance of the endoscopic ultrasound (EUS).

with clear-cut border between the hepatic segment 4 and 2 as noted on endoscopic ultrasound (EUS) (figure 2) was successfully aspirated. The aspirated biliary fluid showed no growth of organisms on culture. Occlusion cholangiogram during the ERCP procedure showed small calibre intrahepatic biliary system with no obvious extravasation of contrast. His symptoms resolved and laboratory values normalised over the following days.

A biloma is a localised collection of bile within the abdomen usually as a result of bile duct injury. They can be differentiated based on their location to be either intrahepatic or parahepatic. Bilomas are mostly asymptomatic but may present with abdominal pain, fever, jaundice or rarely peritonitis. ${ }^{1}$ They are identified as homogeneous collection on a CT or MRI scan. It is one of the uncommon complications of transarterial chemoembolisation (TACE) usually while treating hepatocellular carcinoma. ${ }^{1}$ This is one of the few cases reported in a patient after transarterial embolisation for traumatic liver injury. ${ }^{3}$ The risk factors that contribute to this rare complication includes underlying liver pathology such as cirrhosis of the liver, number of TACE procedures, prior liver resection, dilated common bile duct and use of polyvinyl alcohol for the procedure. ${ }^{1}$ The mechanism behind this phenomenon is poised secondary to ischaemia of intrahepatic bile ducts which obtain their blood supply from the hepatic artery. ${ }^{3}$ In our case, due to the complex hepatic laceration and pseudoaneurysms development in segment 4 and 8 of the liver, there was a concern of a developing tract connection between the two segments. It is likely that some of the gel foam used to embolised the segment 8 vessel 
strayed and affected segment 4 as well. An important common differential for biloma formation is direct trauma to the bile duct especially in patients with complex lacerations in the liver due to MVA. In this particular case, the biloma did not appear during initial abdominal imaging and even after repeat imaging immediately after transarterial hepatic embolisation. The biloma

\section{Patient's perspective}

This was an eye-opening experience for me. I am emotionally shocked after this incident. I am thankful for the minimally invasive procedure performed without the need for any open surgery. I am more than willing to share my experience with the medical community and kindly communicate with me after acceptance of the article.

\section{Learning points}

- Intrahepatic arterial embolisation could be a life-saving modality for various critical and life-threatening hepatic lacerations and bleeding, it is important to recognise that biloma can be one of the serious complications.

- A high clinical suspicion to obtain imaging is necessary when a patient postembolisation presents with symptoms and laboratory parameters concerning for a biloma.

- Most of the cases can be treated conservatively. However, any signs of infection or enlarging size of the biloma should prompt endoscopic or per-cutaneous drainage. was identified only after 9 days postprocedure and this is due to increasing bilirubin levels and low-grade fever. A delayed biloma due to bile duct injury was entertained but an occlusion cholangiogram during the ERCP showed intact and patent intrahepatic biliary system. Most of the cases can be treated conservatively. However, any signs of infection or enlarging size of the biloma should prompt endoscopic or percutaneous drainage.

Contributors Conception and design, acquisition of data or analysis, and interpretation of data: ARH and JEY. Drafting the article or revising it critically for important intellectual content: ARH, JEY and HP. Final approval of the version published: SS and JEY. Agreement to be accountable for the article and to ensure that all questions regarding the accuracy or integrity of the article are investigated and resolved: JEY.

Funding The authors have not declared a specific grant for this research from any funding agency in the public, commercial or not-for-profit sectors.

Competing interests None declared.

Patient consent for publication Parents/Guardian consent obtained.

Provenance and peer review Not commissioned; externally peer reviewed.

\section{ORCID iDs}

Amit R Hudgi http://orcid.org/0000-0002-3062-7694

John Erikson Yap http://orcid.org/0000-0002-0441-3211

\section{REFERENCES}

1 Zhaolin Z, Xuelian L, Wensou H, et al. [Clinical features and risk factors of biloma formation after transcatheter arterial chemoembolization]. Zhonghua Yi Xue Za Zhi 2015:95:1002-5.

2 Huang C-K, Chen S-C, Shih PM-C, et al. Biloma following transcatheter arterial chemoembolization with microspheres: a case report. Kaohsiung J Med Sci 2007;23:470-4

3 Zhang B, Guo Y, Wu K, et al. Intrahepatic biloma following transcatheter arterial chemoembolization for hepatocellular carcinoma: incidence, imaging features and management. Mol Clin Oncol 2017;6:937-43.

Copyright 2021 BMJ Publishing Group. All rights reserved. For permission to reuse any of this content visit

https://www.bmj.com/company/products-services/rights-and-licensing/permissions/

BMJ Case Report Fellows may re-use this article for personal use and teaching without any further permission.

Become a Fellow of BMJ Case Reports today and you can:

- Submit as many cases as you like

- Enjoy fast sympathetic peer review and rapid publication of accepted articles

- Access all the published articles

Re-use any of the published material for personal use and teaching without further permission

Customer Service

If you have any further queries about your subscription, please contact our customer services team on +44 (0) 2071111105 or via email at support@bmj.com.

Visit casereports.bmj.com for more articles like this and to become a Fellow 